\title{
A highly flexible laboratory setup to demonstrate granular flow characteristics
}

\author{
With special emphasize on education and science communication
}

\author{
Thomas Heinze ${ }^{1}$ (D)
}

Received: 19 February 2020 / Accepted: 18 August 2020 / Published online: 28 August 2020

(c) The Author(s) 2020

\begin{abstract}
Dynamics of snow avalanches or landslides can be described by rapid granular flow. Experimental investigations of granular flow at laboratory scale are often required to analyze flow behaviour and to develop adequate mathematical and numerical models. Most investigations use image-based analysis, and additional sensors such as pressure gauges are not always possible. Testing various scenarios and parameter variations such as different obstacle shapes and positions as well as basal topography and friction usually requires either the construction of a new laboratory setups for each test or a cumbersome reconstruction. In this work, a highly flexible and modular laboratory setup is presented based on LEGO bricks. The flexibility of the model is demonstrated, and possible extensions for future laboratory tests are outlined. The setup is able to reproduce published laboratory experiments addressing current scientific research topics, such as overflow of a rigid reflector, flow on a bumpy surface and against a rigid wall using standard image-based analysis. This makes the setup applicable for quick scenario testing, e.g. for hypothesis testing or for low-cost testing prior to large-scale experiments, and it can contribute to the validation of external results and to benchmarks of numerical models. Small-scale laboratory setups are also very useful for demonstration purposes such as education and public outreach, both crucial in the context of natural hazards. The presented setup enables variation of parameters such as of slope length, channel width, height and shape, inclination, bed friction, obstacle position and shape, as well as density, composition, amount and grain size of flowing mass. Observable quantities are flow type, flow height, flow path and flow velocity, as well as runout distance, size and shape of the deposited material. Additional sensors allow further quantitative assessments, such as local pressure values.
\end{abstract}

Keywords Landslides · Granular flow $\cdot$ Laboratory setup · Education · Outreach

Thomas Heinze

thomas.heinze@rub.de

1 Hydrogeology Department, Institute of Geology, Mineralogy and Geophysics, Ruhr University Bochum, Universitätsstr. 150, 44801 Bochum, Germany 


\section{Introduction}

In general, a granular material is defined as discrete particles whose interspace is filled with a liquid or gas. Therefore, many rapid natural and gravity-driven flows such as rock or snow avalanches can be summarized under the term of rapid granular flows. There is a great variety of scientific experimental setups to study granular flows, some designs dating back decades. Most of the apparatus used today cover a one- to two-meter-long slope with $0.1-0.2-\mathrm{m}$-wide channels and are equipped with high-quality camera setups with high frame rates, which can be used to determine particle velocity and flow height (e.g. $\mathrm{Ng}$ et al. 2017; Choi et al. 2016; Chung et al. 2019). The general setup did not change much over the last decades (cf. e.g. Iverson and Lahusen 1989; Hutter and Koch 1991; Koch et al. 1994). Some of the equipments include sensors such as pressure gauges at the bottom or soil moisture sensors for multi-phase environments (e.g. Eckersley 1991; Lee et al. 2011; Spolverino et al. 2019). Studying interaction of granular flow with different kinds of obstacles and protection measures is a common goal of laboratory studies (cf. Choi et al. 2016; Cui et al. 2018; Ng et al. 2018). But also the effect of complex topography and channel geometries is a recent research topic (e.g. Faug et al. 2015; Viroulet et al. 2017). As a drawback, modifying most of these experiments to test various channel designs and features, such as inclination, channels width, slope surface, is mostly connected to a cumbersome re-assembling. These channels often require significant funds as well as trained personnel for service. They are mostly stationary and are only available in a limited number per laboratory (e.g. de Jager et al. 2017). Further, there are small-scale experiments handmade for demonstration, education and scientific testing, but those often lack flexibility and are seldom constructed for interactive use (e.g. Spence and Guymer 1997). However, in scientific research there are use cases for which complex setups are too costly and laborious, e.g. for an independent validation and reproduction of experiments during the review process, for hypotheses testing or for validating numerical models.

Public education on natural hazards is crucial for hazard mitigation as public awareness and basic understanding of the hazard dynamics can help to minimize fatalities and damage (Smith 2004; United Nations 2015). As an example, inconsiderate actions of hikers and skiers cause snow avalanches each year as the hazard is underestimated or remains unrecognized. Perception of the hazard in the general public will generate appreciation for hazard-reducing measures, such as urban management, construction of protection devices and further scientific work (United Nations 2015). On the other hand, a dialog between professionals and members of the general public can contribute to hazard mitigation as, for example, traditional knowledge of communities can be complementary to scientific observations (Mercer et al. 2012; Marín et al. 2020). For volcanic hazards it is known that the personal perception of hazard and its relativization influences the willingness to adopt hazard-mitigating measures (Paton et al. 2008). This individual hazard perception can also influence the formal hazard assessment (Plattner et al. 2006). Besides the hazard perception, the hazard awareness of parts of the general public can ask for actions by administration and/or science as for example teachers and students in a school districts affected by the 2008 Wenchuan earthquake demanded disaster-related curricula (Zhu and Zhang 2017). For landslides, a one-semester course in the 6th grade at an elementary school in Brazil has been shown to increase students hazard awareness and to connect theory with the real hazard the school community faces (de Mendonca and Valois 2017). From a general perspective in natural science education, natural hazards are a great chance to present various aspects of natural sciences in a real-life example, such as fluid dynamics or solid mechanics. Real-life examples are known to increase the attraction 
of science classes (Lyons 2006), and landslides and avalanches are part of science education across several age groups. They are discussed in more detail in subjects such as civil engineering, engineering geology, geomorphology, geography, geophysics and sedimentology. It is state of the art that self-experience and demonstration of phenomena contribute to a better understanding of science (e.g. Montessori 1956; Lewin 1981; Kolb 1984). Small-scale classroom experiments and demonstration of phenomena are therefore a crucial contribution to science education and communication (Turkay and Adinolf 2012; Muller et al. 2013; Pereira et al. 2014). Such interactive experience is known to invoke interest in science early and across all age groups, and therefore, small experiments of granular flow can be helpful to deliver the message to students as well as the general public (Buncick et al. 2001; Maltese and Tai 2010). More recently, there is a significant movement, making science education and especially the topic of natural hazard more intuitive for students and society, e.g. through interactive games (Mossoux et al. 2016; Gires et al. 2016; Terti et al. 2019).

A need for a small, highly flexible and low-cost experimental setup that satisfies scientific standards, is affordable, easy to handle and robust at the same time to enable interactive experiments by users were identified. Especially in science education, experiments always educate twofold: about the scientific content and about scientific work procedures. Therefore, emphasis has been given to an experimental design that enables reproducible experiments, reduces undesired influences, such as boundary effects, and allows access to many crucial parameters such as runout distance, size and shape of the deposited material, flow type, flow height, flow path and flow velocity depending on the additional equipment used. Flexibility in the design setup to allow parameter variations such as slope length, channel width and height, inclination, bed friction, slope shape, obstacle position and shape, density, composition, amount and grain size of flowing mass, is crucial. Such an experimental setup should still satisfy higher scientific expectations on qualitative and quantitative reproducibility in the display of process dynamics. The LEGO systems, a well-known Danish brand for kid toys based on binding blocks, enables construction of a channel for granular flow experiments. Its system of binding bricks is highly flexible, and a large number of complex bricks exist, such as joints. The variety in bricks allows a highly flexible and modular design of the experimental apparatus with an almost infinite number of design possibilities. The bricks used in the design presented here would cost less than $€ 70$ if bought new. The apparatus can quickly be assembled and reassembled, making it highly portable and requires almost no room for storage. Originally designed as toys, the bricks are robust and safe for children above an age of seven, though the experiments discussed in this work address high school or university students. However, the principal setup can also be used in simpler configurations for addressing children, age seven or above, and the general public.

In this work, an exemplary design and possible variations of such a demonstration apparatus for granular flows are presented. The experimental results are quantitatively analyzed and verified through comparison to theoretical expectations and previous scientific work. In the outlook extensions of the presented laboratory setup are discussed to address recent open research questions on granular flow, such as erosion or submarine granular flow.

\section{Theoretical background}

A granular medium is a conglomerate of discrete solid particles with a diameter larger than $1 \mu \mathrm{m}$, so that Brownian motion can be denied (Pudasaini and Hutter 2007). There is no upper limit for the diameter as even large boulders can be described as granular material 
(Pudasaini and Hutter 2007). Many food components such as cereals, coffee, beans, rice, sugar are also granular materials, showing effects of characteristic granular features such as segregation, dilatancy and fluidization. The probably most prominent granular material in nature is sand. Its dynamics in deserts and at coasts are great examples of granular media strongly influencing landscape formations. Rapid granular mass flows, such as landslides, volcanic flows and avalanches, can be further subdivided depending on their origin and the involved material. For example, snow avalanches can be divided into powder and dense flow: powder snow avalanches are dominated by the gaseous phase between the solid particles, while dense snow avalanches mostly depend on the solid particle movement (Hopfinger 1983).

In general, the dynamics of rapid granular mass flows are governed by the conservation of mass and momentum. The most common macroscopic mathematical model to describe free surface, downslope gravity-driven granular flow is the depth-averaged Savage-Hutter model (cf. Savage and Hutter 1991), which has shown great success in reproducing laboratory and field observations. The three most prominent forces are gravity as driving force, which is counteracted by the basal friction and the longitudinal pressure. The longitudinal pressure is responsible for the shape of the flowing mass by accelerating mass at the front and deceleration at the rear. While the gravitational force is controlled by gravitational acceleration and the inclination angle of the slope, the basal friction depends on inclination and the friction coefficient, if Coulomb-type friction is assumed (Fei et al. 2012). Velocity-dependent friction models also exist (Pouliquien and Forterre 2002). The lateral pressure, depending on the chosen model, can be calculated using the earth pressure coefficient, expressing the ratio of vertical to horizontal stress. It can be theoretically calculated e.g. by the Coulomb model introducing angle of internal friction and basal friction coefficient, which is therefore a crucial parameter controlling the granular flow. In curved and twisted channels additional effects occur such as local deceleration and mass deposition due to a loss in kinetic energy (Pudasaini et al. 2008). On the other hand, the basal friction can be reduced or increased through centripetal forces in curves (Greve and Hutter 1993). The presence of pore pressure can further influence the flow by reducing normal load, decreasing frictional forces and causing segregation processes. The models discussed above were developed for single or multi-phase flow based on continuum mechanics. It has been assumed that the granular material behaves as such a continuum and can be described by the conservation laws of mass and momentum, respectively. These depth-averaged models further assume that the vertical variation of parameters and variables, such as velocity, is negligible as usually the lateral spread of mass is much larger than the flow depth.

Protective measures against hazardous granular flow are usually solid obstacles aiming at reducing the acceleration of the moving mass and its momentum. Large metal nets are well known along roads and train tracks, preventing the mass to fall or slide onto the roads or tracks (Margreth 2007). Several defensive structures are not aiming at stopping a granular mass flow but at guiding its direction, reducing the amount of involved mass or slow down its acceleration. Solid structures of a pyramidal shape with one edge towards the direction of the flow are common examples of such defensive structures (Jóhannesson 2001), but obstacles can also cause shock waves when the front of the flowing mass hits the obstacle (cf. experiments in Hauksson et al. 2007). Forests are a good natural structure at slowing down hazardous granular flows or even stopping its initiation (cf. Bebi et al. 2009). To stop a fully developed large granular flow, usually solid structures such as walls or other kinds of obstacles are necessary (cf. Jóhannesson and Hákonardóttir 2003; Jiang and Towhata 2013). Such structures need to withstand the stagnation pressure of the granular flow, which depends on density, friction angle and original flow velocity squared (cf. 
experiments in $\mathrm{Ng}$ et al. 2018). Dimensioning and locating flow inhibiting or flow-guiding obstacles is a non-trivial task with optimal results being sometimes counter-intuitive and new designs and constructions are developed continuously (cf. $\mathrm{Ng}$ et al. 2017).

\section{Experimental design and its variation}

The base unit of the experimental apparatus used in this work is base plates of 6.4 times $12.7 \mathrm{~cm}$, which are joined together at the back. Those base plates are available either with a smooth surface or with the typical LEGO surface consisting of small knobs used for combination of other bricks (Fig. 1a-1\&2). Those plates are used to build the sliding surface (Fig. 1d). There is no limitation on the number of plates to be combined besides the pieces available. Therefore, there are no restrictions in length or width of the inclined slope. Typical LEGO bricks (Fig. 1a-9) are used to build a tower combined with flexible joints to hold the inclined slope in place (Fig. 1c). Such a typical brick is roughly $1.1 \mathrm{~cm}$ high, but can be combined with thinner bricks of $0.3 \mathrm{~cm}$ height (Fig. 1a-7). The knobs on the surface have a height of roughly $0.1 \mathrm{~cm}$, which is merged with the bottom of a connected brick, so the total height of two bricks is $2.1 \mathrm{~cm}$ instead of $2.2 \mathrm{~cm}$. The joints consist of two standard plates with knobs combined by a pivot joint (Fig. 1a-11). As the joints use the standard LEGO system as all other bricks, the chute can move relatively to the joints and the tower, because the joints can be combined with the inclined surface almost anywhere on the plates backside and so the inclination angle can be adjusted seamlessly (Fig. 1c). Bricks can also be used to construct channel walls. There are also transparent see-through bricks, which allow visual observation through the channel wall, e.g. to record flow height and velocity (Fig. 1a-6). Based on the structure in which the knobs are arranged on the bricks, the minimum change of channel width is $0.8 \mathrm{~cm}$. The release mechanism can also be designed based on LEGO bricks by using one of the before-mentioned thin plates (Fig. 1a-1) of suitable width to seal the mass-holding chamber (Fig. 1b, c). The plate can be connected with a round brick and other matching bricks that can be connected to the side walls. Finally, attaching a cord to the slope using another type of brick, an opening upwards release mechanism has been implemented (Fig. 1b). There are no restrictions on where to place the release mechanism, and there are no restrictions on the size of the mass-holding chamber. Due to the standard design of the knobs on top of each brick, the minimum change in any brick position is $0.8 \mathrm{~cm}$. The horizontal runout zone can be build out of similar plates either smooth or with knobs. Obstacles or other structures can be installed also on the horizontal runout zone, using the same technology as on the inclined slope. The usage of other smooth surfaces such as wood or glass at the horizontal runout zone is also possible though affecting the physics of the flow due to a change in surface roughness. Usually a seamless transition from the inclined slope to the horizontal is possible. Small amounts of modelling clay can be used to cover small gaps when present while using different types of materials.

Additionally to the rather standard bricks described above and used to build the base of the proposed design, there is a great number of diverse bricks that can be used to modify the flow path. For example, barrel-shaped bricks can be used as obstacles (Fig. 1a-10), as well as triangular or circular bricks; bricks with various inclinations (Fig. 1a-3-5) can be used as bumps (cf. experiments in Greve and Hutter 1993; Faug et al. 2015; Chung et al. 2019) or curved bricks to model a curved slope (cf. experiments in Viroulet et al. 2017). The variety of bricks and their almost free positioning on top of the bottom plates allows combination of various slope shapes and geometries 


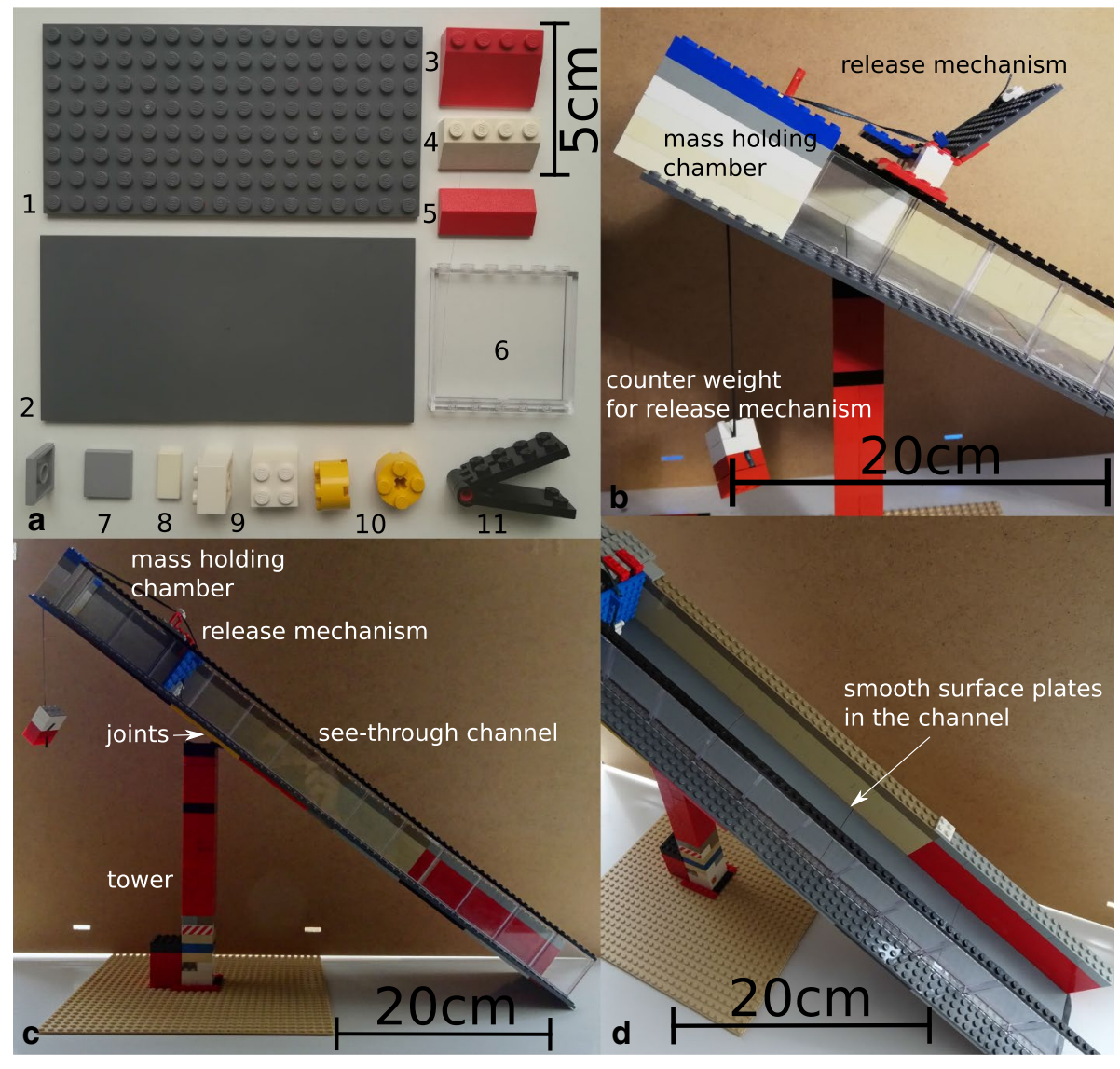

Fig. 1 Used LEGO bricks (a), release mechanism (b, c) and possible constructions with a smooth plane surface $(\mathbf{c}, \mathbf{d})$

along one flow path, even for various inclinations along one paths (cf. experiments in McDougall and Hungr 2005). Further, as all bricks are made out of plastic, they can easily be covered by any other material such as plastic sheets or sandpaper to modify wall or bottom surface friction. Beside such covers, the smooth and knobby surface already provides two different types of surfaces, though the quantitative determination of surface roughness is yet to be performed. The bricks used to build the channel wall or used as obstacles can also be combined with modelling clay or plasticine because they are washable and reusable afterwards (cf. Iverson et al. 2004). Using additional materials such as plasticine around conventional LEGO bricks allows arbitrary shapes, while the bricks provide stability and simple connectivity.

Besides size restrictions, there are no limitations on the nature of granular materials used in the apparatus. It has been successfully tested with different kinds of gravels and sands but also using lentils and rice. 


\section{Exemplary results}

While a large number of more simple experiments are possible with the presented setup, some more advanced and elaborated experiments are presented in the following to showcase the flexibility of the used apparatus. As granular material common lentils with an elliptic shape with round base with a diameter of $0.5 \mathrm{~cm}$ and a height of $0.2 \mathrm{~cm}$ were used as well as spherical plastic beads with a diameter of $0.3 \mathrm{~cm}$ (Fig. 2), the lentils have been sorted to remove broken ones as well as pieces. During the course of the experiments no alteration of the lentils was observed. All video footage was recorded with a regular smartphone camera with a frame rate of $120 \mathrm{fps}$.

The choice of granular material has been based on several selection criteria. First of all, the experimental setup as used in the experiments presented below imposes a lower and upper limit on the grain size. Due to the width, height and length of the chute, particles with a diameter larger than $1 \mathrm{~cm}$ experienced substantial boundary effects through wall friction and did not move in a continuous stream of particles as interparticle space became increasingly large. For such large particles the flow is dominated by interparticle moment transfer and the flow becomes strongly non-homogeneous in all three spatial dimensions, which is not the scope of this work. Through the electrostatic attraction of the plastic bricks, flow of small grains with diameters smaller than $0.1 \mathrm{~cm}$ would be influenced at the bottom of the flow and material would be deposited along the flow path, altering the total amount flowing mass. The chosen granular particles match the suitable geometrical grain size and represent different kinds of grains through their different shapes, sizes and densities. While the grain shape has not been considered in detail in this work, different grain densities were required to reproduce the various experiments from literature examples shown below.

\subsection{Overflow of a rigid reflector}

The setup presented here is constructed based on the designs of Choi et al. (2016) and $\mathrm{Ng}$ et al. (2017). The principal objective of those studies is testing the applicability of innovative protection designs, in this case an adoption from sea wave protection measures, for landslides. Granular materials behave differently from pure water in several critical aspects, e.g. by piling up in front of the obstacle facilitating overflow of the barrier, so that reflector

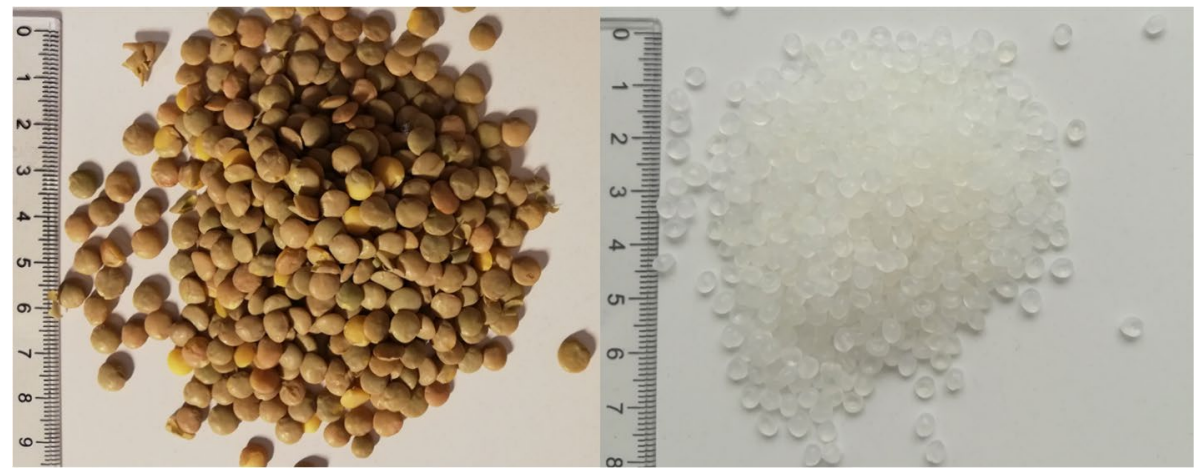

Fig. 2 Used granular materials: lentils and plastic beads 
design needs to be improved. Key aspects to study in those experiments are the existence of dead zones, in which there is no particle movement, and the maximum overflow velocity. The presented experiments below have been conducted using the previously described experimental equipment to construct a $75-\mathrm{cm}$-long and 8-cm-wide channel with an inclination of $40^{\circ}$. After a distance of $42 \mathrm{~cm}$ from the gate, a rectangular reflector of $3 \mathrm{~cm}$ height and a crest of $2 \mathrm{~cm}$ was installed vertical on the slip surface (Fig. 3a). In opposition to the before-mentioned manuscripts, reflector geometry, length, position, orientation angle etc., have not been varied as this would be out of scope for this study. However, such variations would be easily doable considering the flexibility of the presented setup. Lentils were used as the flowing material because they allow a better visual detection. Similar results can be obtained using plastic beads.

Once the tip of the flow reaches the rigid reflector, a shock wave is generated and the particle flow changes direction for a short time as particles are flowing vertical to the surface (Fig. 3a, b). Then, over time, the dead zone in which the particles do not move anymore is growing uphill starting from the reflector with a maximum height of the deposit matching the height of the reflector (Fig. 3b). Dead zones can be clearly identified by the resting particles in contrast to the dynamic overflowing stream. The flow height of the overflowing material is comparable to the height up the upstream flow (Fig. 3c-f). After the reflector, the flow height increases as interparticle distance increases (Fig. 3c-e). The geometrical shadow behind the reflector, in which no grain is entering, is growing with

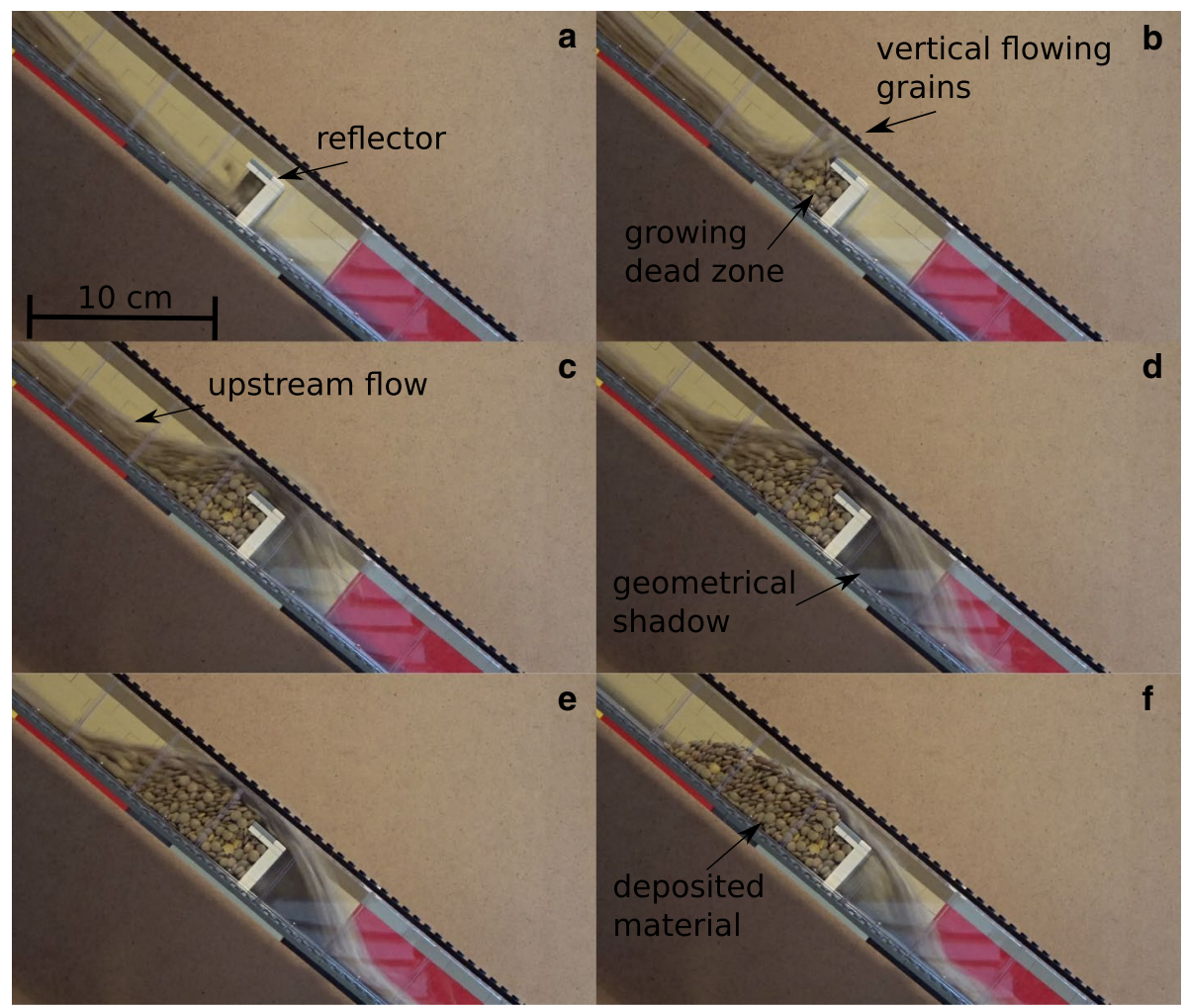

Fig. 3 Particle flow at a $240 \mathrm{~ms}$, b $320 \mathrm{~ms}$, c $400 \mathrm{~ms}$, d $480 \mathrm{~ms}$, e $560 \mathrm{~ms}$ and f $720 \mathrm{~ms}$ after flow initiation 
increasing amount of deposited material in front of the reflector (Fig. 3c, d), but the geometrical shadow becomes smaller once there are fewer amounts of mass and the flow velocity declines (Fig. 3e, f). The results presented here are in very good agreement with the results presented in Choi et al. (2016) and Ng et al. (2017) because similar observations have been made by those authors with respect to shock wave generation, vertical grain movement parallel to the reflector wall, growing dead zone, overflowing grains once sufficient mass has been deposited in front of the reflector as well as with respect to flow heights and geometrical shadow.

\subsection{Flow on a bumpy surface}

This scenario is primarily based on the experiments presented in Viroulet et al. (2017). The basal surface has a strong influence on the granular flow as e.g. the basal surface roughness is responsible for loss of kinetic energy or bumps and curvature can either accelerate or decelerate the flow through additional forces. Local alterations of the basal topography can especially change the granular flow behaviour to a more liquid- or even gaseous-like one with a locally large interparticle distance and direct particle interaction by collision dominating the solid flow behaviour. The installation of hazard mitigation techniques can become obsolete if the basal topography is not considered. In this specific experiment, a bump is installed to test the capabilities of different computer models to reproduce the take-off point of the generated jet. Focus is set to the transition from an initial jet to a steady-state stream due to the deposition of material in front of the bump. The presented experiments in this work were done using a 52-cm-long and 12-cm-wide channel with an inclination of $27^{\circ}$. After a distance of $40 \mathrm{~cm}$ from the release mechanism, a soft bump with a peak height of $2 \mathrm{~cm}$ was introduced. The downhill side of the bump was a bit steeper with an inclination of $60^{\circ}$ in comparison with $45^{\circ}$ inclination uphill relative to the inclined plane (Fig. 4a). This is a derivation from the setup as presented in Viroulet et al. (2017) who used a symmetrical bump. The derivation from the original experiment is done simply for demonstration of the capability to easily introduce smooth steps into the sliding plane. The change in geometry does not significantly influence the physical interpretation of the results, as will be shown below. As granular material, the spherical plastic beads were used due to their lower density and similar grains were used in the original publication by Viroulet et al. (2017).

The images from the camera recording were transferred to greyscale for an improved contrast of the transparent plastic beads with respect to its surrounding. The sequence of images shows nicely the laminar downhill slope and its transition into a shockwave with turbulent particle motion once reaching the bump (Fig. 4b, c). During the turbulent phase at the front of the flow, various particle directions can be observed, showing the influence of the obstacle on separating individual particles from the continuous stream (Fig. 4c). As material is deposited in front of the bump, the flow changes into a steady stream (Fig. 4d). The steeper downslope side of the bump did not affect the flow in any significant manner, as the stream touches the downhill surface only after the initial shockwave and during steady stream development (Fig. 4e). The final deposition at the bump is equal to the height of the bump (Fig. 4f). The stream flow shows significant turbulence at the free surface, and flow height is different on both sides of the bump (Fig. 4e). Again, the results presented here agree very well with the results presented in the initial manuscripts of Viroulet et al. (2017) as similar observations with regard to flow behaviour, deposition and flow height. 


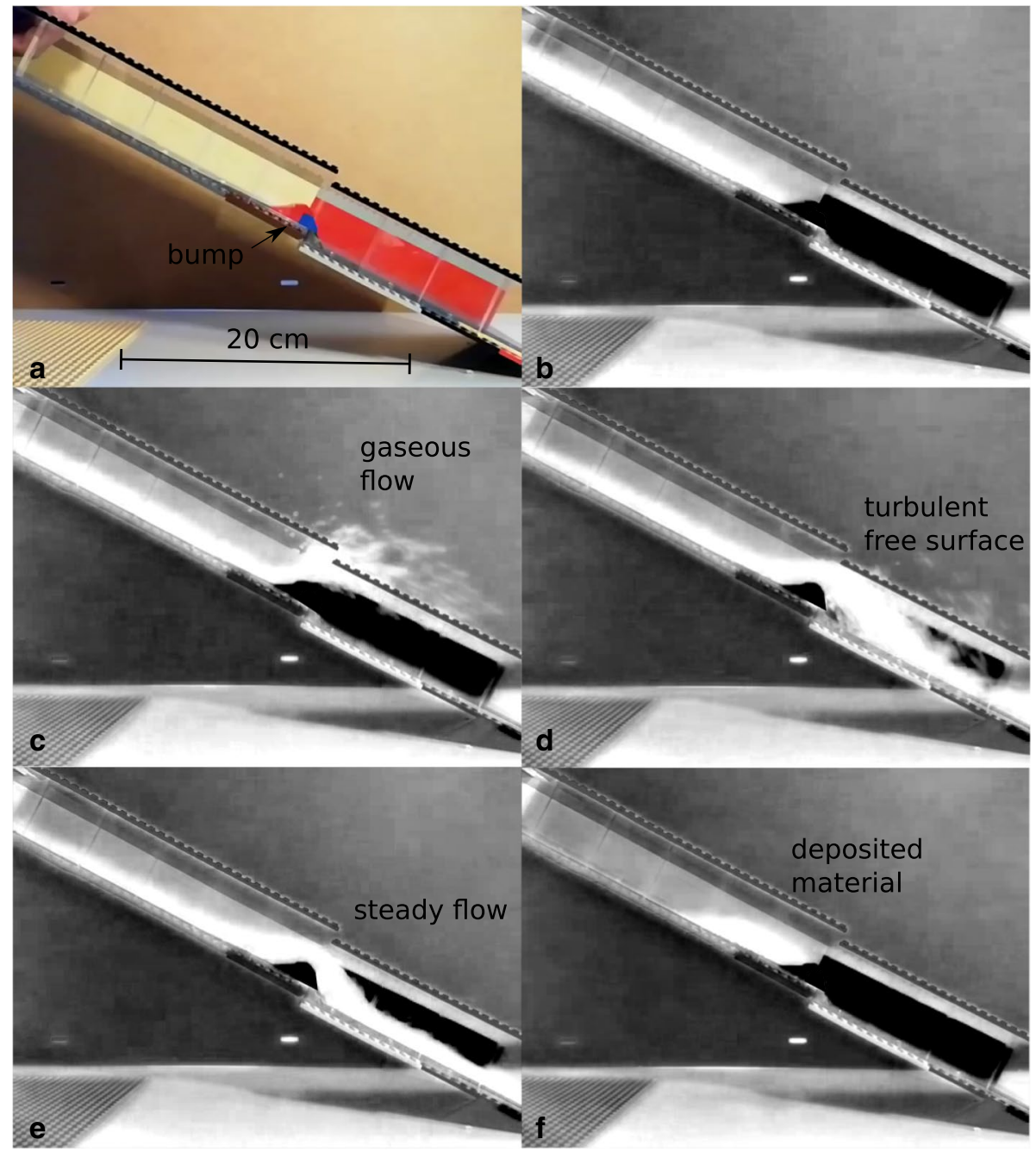

Fig. 4 a Initial setup. Particle flow at b $264 \mathrm{~ms}$, c $376 \mathrm{~ms}$, d $496 \mathrm{~ms}$, e $608 \mathrm{~ms}$ and f $1976 \mathrm{~ms}$ after flow initiation

\subsection{Flow against a rigid wall}

Granular flow against a rigid wall is probably one of the most classic experimental setups with regard to landslide protection. The experimental setup shown here is comparable to the design used in Teufelsbauer et al. (2009), in which the variation of deposition pattern is analyzed in dependence of wall height. Attention is especially paid to the (dis-)continuous spatial distribution, w.r.t. horizontal spreading and height, of particles in the deposit. Depending on the capability of the particles to overflow or to flow around the wall, the shape of the deposit changes. In the work of Teufelsbauer et al. (2009), the experiments are used to validate a numerical discrete particle model and identify critical parameters in 
the used modelling approach. The experiments also nicely demonstrate the granular flow behaviour around rigid obstacles spreading into the geometrical shadow depending on flow mass, obstacle dimensions, inclination and slope length. In the experiments presented here, the previously characterized lentils have been used because of their good visual detectability. The lentils were released in a $16 \mathrm{~cm}$ distance from the 1.6-cm-thick wall on a smooth inclined plane with $35^{\circ}$ inclination. The release chamber had a hemispherical shape. The distance from the obstacle to the horizontal was $8 \mathrm{~cm}$.

The deposit displays two heaps, one of each side of the wall, for all wall heights, but the separation of the heaps becomes more distinct with increasing wall height (Fig. $5 \mathrm{~g}-\mathrm{i})$. It can further be clearly seen that the wall is withholding larger amounts of particles within a characteristic pyramidal shape with increasing height. While the pyramidal shape is incomplete for the lowest wall height, it is not changing significantly from a wall height of 4-8 $\mathrm{cm}$. However, particles resting on top of the wall for the intermediate height indicate that particles have overflown the wall. This can also be clearly seen in the lateral as well as the top view during the experiments (Fig. 5a-f). For the wall heights smaller than $8 \mathrm{~cm}$, particles flow over the wall, though for a wall height of $4 \mathrm{~cm}$ these are only very few particles (Fig. 5e). For the wall heights of 4 and $8 \mathrm{~cm}$ a dead zone is visible in which particles do not move or at least do not move downslope (Fig. 5e, f). Also for those both wall heights there is a protected area behind the wall in which there are none or only very few particles during the flow (Fig. 5e, f). If the top wall friction has a substantial influence on the flow, smooth tiles on top of the wall could be applied or thinner bricks used to build the wall. Both ways are easily realizable using LEGO bricks. The results obtained from those comparably

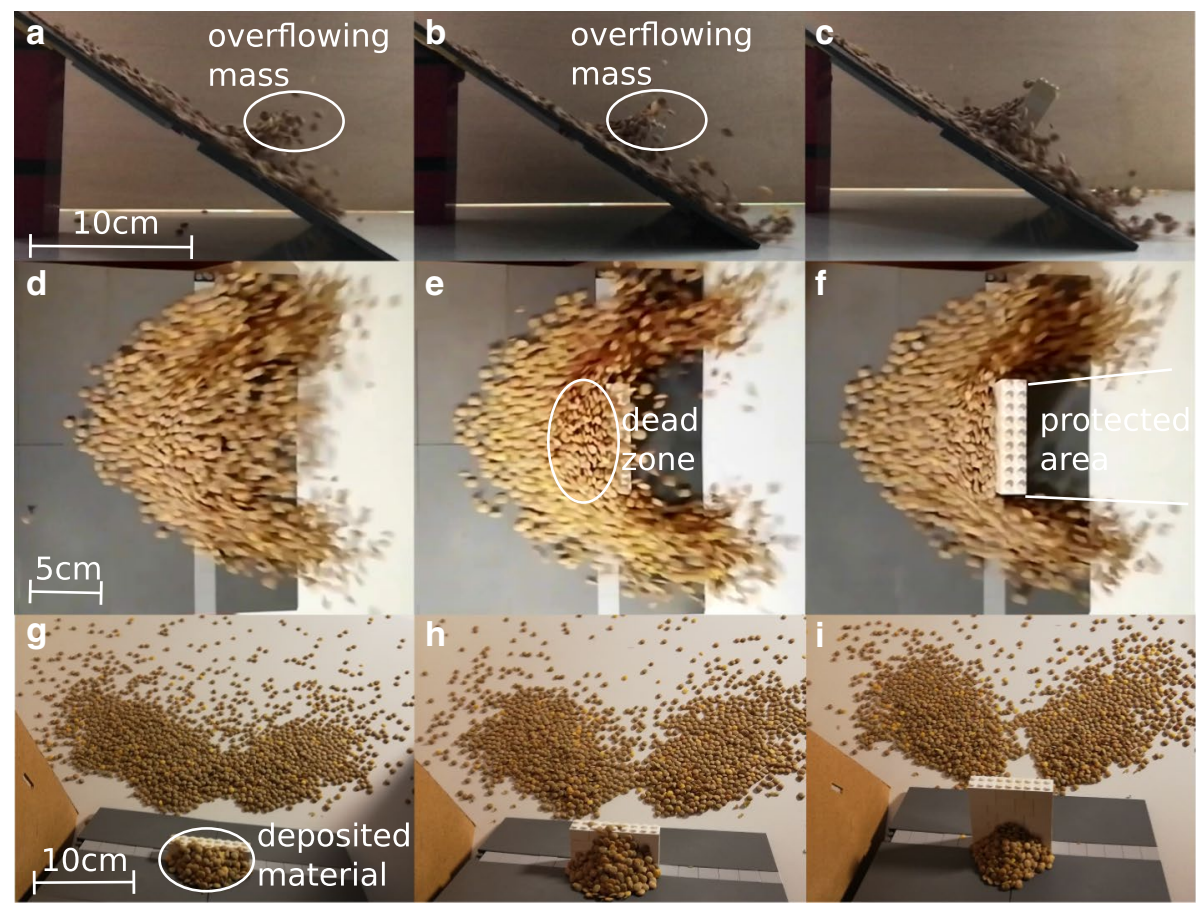

Fig. 5 Granular material deposited after flow against a rigid wall of $\mathbf{a} 2.1 \mathrm{~cm}, \mathbf{b} 4.1 \mathrm{~cm}$ and $\mathbf{c} 8.1 \mathrm{~cm}$ height 
simple experiments show a very good agreement with the results presented in (Teufelsbauer et al. 2009), e.g. with respect to the spread of the deposit on the horizontal as well as in front of the wall, the generation of dead zones in front of the wall depending on wall height, overflow of the wall at lower wall height and shape of the protected area behind the wall relative to the wall width.

\section{Discussion}

In this work, a highly flexible laboratory setup to demonstrate granular flow characteristics has been introduced. Based on a standardized toy system a great number of experimental setups and scenarios could be tested. In the described setup, quantitative assessment of the experimental results was limited through the lack of sensor installations. Naturally, sensors such as pressure gauges could be combined with the presented setup. However, sensor installation could require a larger spatial extent of the setup due to the size of the sensors or damage of bricks, e.g. for cable routing, though the brittle behaviour of the plastic bricks might be a limit through limited deformation and sharp corners. On the other hand, from the large number of available LEGO bricks, e.g. including hollow bricks or bricks with holes, several ones might facilitate the installation of sensors. With plastic as primary or solely component of the setup, sensors can be easily glued into the setup and the bricks are electric isolators for cable routing. However, heat generated from electric parts causing temperatures above $80^{\circ} \mathrm{C}$ might damage the bricks. Analysis of video footage allows derivation of flow height and flow type (turbulent, laminar) as well as, if recorded with highspeed cameras with more than 300 frames per second, the flow velocity can be determined through particle image velocimetry (PIV). In PIV the particle motion is derived from pixel displacements between subsequent images of the video footage so that the velocity field of the flow can be obtained. Mass deposit along the runout can also be quantitatively examined in terms of its geometrical spread from images. To contribute, e.g. to the validation of numerical models obtained, experimental data can be analyzed quantitatively through measurements of flow height, flow type and flow velocity through video recording, through measurements of the deposited material in terms of shape, size/mass (cf. Teufelsbauer et al. 2009), horizontal runout distance, as well as through possible sensor installations. The presented setup enables the variation of a large set of parameters such as of slope length, channel width, height and shape, inclination, bed friction, obstacle position and shape, as well as density, composition, amount and grain size of the flowing mass.

Great success has been made using the presented apparatus in higher education in several courses at German Universities in subsequent years. The popularity and well-known toys character allows easy interaction through the students with a low inhibition threshold. Due to the easy brick-combining technology, parameter variations can easily be demonstrated, facilitating the understanding of complex mathematical models. Many students have been familiar with the system already or caught the idea quickly. In those courses, even grown-up students showed great joy on working with such a system, increasing the participation in the course and stimulating their creativity, both in improving the experimental design and in possible scenarios. The unbreakable items enable experiments performed by the students allowing hands-on experience. Similar experience has been made at public presentations. In particular, children up to an age of 14 seemed attracted by the use of a familiar toy system but also for adults the flexibility of the design has been found useful for demonstrations. 
The most obvious limitation of the presented setup is size, due to the increase in required bricks. While there are constructions using LEGO bricks at meter scale, this will not be costefficient for the purpose of this work. With the physical size limitation comes a limitation on the amount of sliding mass that can be used with the presented material. Up to several hundred grams of material have been applied successfully. Due to the size restriction, there are limitations on additional sensor installations as discussed above because of the demands on sensor size. The exemplary results presented in this work show the reproducibility of the presented setup using the available tools and therefore fulfilling basic scientific demands. While in this study standardized materials, such as specific grain sizes or sandpaper to achieve a specific surface roughness, have not been used, this remains possible. If no additional cover, such as sandpaper, is used, electrostatic attraction between the plastic bricks and very small particles, such as sand grains with diameters below $0.1 \mathrm{~cm}$, can have substantial influence on the flow causing particles to stick at the plastic surface. As discussed above, the experimental setup presented here is most suitable for grain sizes between 0.1 and $1 \mathrm{~cm}$, as boundary effects impose an upper boundary on the usable grain size.

\section{Conclusion}

A highly flexible laboratory setup has been presented for investigating a great range of parameters and scenarios. Experimental results from granular flows on top of a bumpy surface and in contact with various obstacles have been shown. The small scale and the used material limit the installation of sensors such as pressure gauges, but visual recording and analysis is possible. Besides the scientific usage of the presented setup in terms of flow analysis, the modular character of the apparatus allows a quick and easy phenomenological demonstration of granular flow characteristics. This can be useful in various situations, e.g. during validation and reproduction of scientific experiments and phenomena during review, during validation of numerical codes or to quickly test large-scale experimental ideas. Due to system being based on a popular toy system, it has been especially successful when used in education and science communication. Further extensions of the apparatus towards submarine landslides, granular flows impacting water reservoirs and erosion experiments are possible because all used parts are water resistant. Naturally, the setup is also not limited to single-phase flow but can be used for multi-phase flows, such as grain-fluid mixtures or combinations of different grain sizes (cf. experiments from Ming Cheng et al. 2019). Implementations of pressure gauges as well as combination with high-speed cameras will enhance the quantitative assessment of the experiments in the future.

Acknowledgements Open Access funding provided by Projekt DEAL. The author very much appreciates the thoughtful comments from the editor, Fabio Dioguardi, and an anonymous reviewer that helped to improve the manuscript.

\section{Compliance with ethical standards}

Conflict of interest The author declares that he has no conflict of interest.

Open Access This article is licensed under a Creative Commons Attribution 4.0 International License, which permits use, sharing, adaptation, distribution and reproduction in any medium or format, as long as you give appropriate credit to the original author(s) and the source, provide a link to the Creative Commons licence, and indicate if changes were made. The images or other third party material in this article are included in the article's Creative Commons licence, unless indicated otherwise in a credit line to the 
material. If material is not included in the article's Creative Commons licence and your intended use is not permitted by statutory regulation or exceeds the permitted use, you will need to obtain permission directly from the copyright holder. To view a copy of this licence, visit http://creativecommons.org/licenses/by/4.0/.

\section{References}

Bebi P, Kulakowski D, Rixen C (2009) Snow avalanche disturbances in forest ecosystems—state of research and implications for management. For Ecol Manag 257(9):1883-1892. https://doi.org/10.1016/j.forec o.2009.01.050, https://linkinghub.elsevier.com/retrieve/pii/S0378112709000851

Buncick M, Betts PG, Horgan DD (2001) Using demonstrations as a contextual road map: enhancing course continuity and promoting active engagement in introductory college physics. Int J Sci Educ 23(12):1237-1255. https://doi.org/10.1080/09500690010025030, http://www.tandfonline.com/doi/ abs/10.1080/09500690010025030

Choi C, Ng C, Goodwin G, Liu L, Cheung W (2016) Flume investigation of the influence of rigid barrier deflector angle on dry granular overflow mechanisms. Can Geotech J 53(10):1751-1759. https://doi. org/10.1139/cgj-2015-0248, http://www.nrcresearchpress.com/doi/10.1139/cgj-2015-0248

Chung Y, Wu C, Kuo C, Hsiau S (2019) A rapid granular chute avalanche impinging on a small fixed obstacle: DEM modeling, experimental validation and exploration of granular stress. Appl Math Model 74:540-568. https://doi.org/10.1016/j.apm.2019.05.003, https://linkinghub.elsevier.com/retrieve/pii/ S0307904X19302860

Cui Y, Choi CE, Liu LH, Ng CW (2018) Effects of particle size of mono-disperse granular flows impacting a rigid barrier. Nat Hazards 91(3):1179-1201. https://doi.org/10.1007/s11069-018-3185-3

de Jager RR, Maghsoudloo A, Askarinejad A, Molenkamp F (2017) Preliminary results of instrumented laboratory flow slides. Proc Eng 175(2016):212-219. https://doi.org/10.1016/j.proeng.2017.01.012, https://linkinghub.elsevier.com/retrieve/pii/S1877705817300127

de Mendonca MB, Valois AS (2017) Disaster education for landslide risk reduction: an experience in a public school in Rio de Janeiro State, Brazil. Nat Hazards 89(1):351-365. https://doi.org/10.1007/s1106 9-017-2968-2

Eckersley D (1991) Instrumented laboratory flowslides. Int J Rock Mech Min Sci Geomech Abstr 28(23):A183. https://doi.org/10.1016/0148-9062(91)93112-J, https://linkinghub.elsevier.com/retrieve/ pii/014890629193112J

Faug T, Childs P, Wyburn E, Einav I (2015) Standing jumps in shallow granular flows down smooth inclines. Phys Fluids 27(7):073304. https://doi.org/10.1063/1.4927447

Fei M, Sun Q, Zhong D, Zhou GG (2012) Simulations of granular flow along an inclined plane using the Savage-Hutter model. Particuology 10(2):236-241. https://doi.org/10.1016/j.partic.2011.11.007

Gires A, Muller CL, Le Gueut MA, Schertzer D (2016) Making rainfall features fun: scientific activities for teaching children aged 5-12 years. Hydrol Earth Syst Sci 20(5):1751-1763. https://doi.org/10.5194/ hess-20-1751-2016

Greve R, Hutter K (1993) Motion of a granular avalanche in a convex and concave curved chute: experiments and theoretical predictions. Philos Trans R Soc Lond Ser A Phys Eng Sci 342(1666):573-600. https://doi.org/10.1098/rsta.1993.0033

Hauksson S, Pagliardi M, Barbolini M, Jóhannesson T (2007) Laboratory measurements of impact forces of supercritical granular flow against mast-like obstacles. Cold Regions Sci Technol 49(1):54-63. https ://doi.org/10.1016/j.coldregions.2007.01.007, https://linkinghub.elsevier.com/retrieve/pii/S0165232X0 7000079

Hopfinger EJ (1983) Snow avalanche motion and related phenomena. Annu Rev Fluid Mech 15:47-76

Hutter K, Koch T (1991) Motion of a granular avalanche in an exponentially curved chute: experiments and theoretical predictions. Philos Trans R Soc A Math Phys Eng Sci 334(1633):93-138. https://doi. org/10.1098/rsta.1991.0004

Iverson RM, Lahusen RG (1989) Dynamic pore-pressure fluctuations in rapidly shearing granular materials. Science 246(June):796-799

Iverson RM, Logan M, Denlinger RP (2004) Granular avalanches across irregular three-dimensional terrain: 2. Experimental tests. J Geophys Res Earth Surf 109(F1):1-16. https://doi.org/10.1029/2003jf000084

Jiang YJ, Towhata I (2013) Experimental study of dry granular flow and impact behavior against a rigid retaining wall. Rock Mech Rock Eng 46(4):713-729. https://doi.org/10.1007/s00603-012-0293-3, http://link.springer.com/10.1007/s00603-012-0293-3

Jóhannesson T (2001) Run-up of two avalanches on the deflecting dams at Flateyri, northwestern Iceland. Ann Glaciol 32:350-354. https://doi.org/10.3189/172756401781819382 
Jóhannesson T, Hákonardóttir KM (2003) Remarks on the design of avalanche braking mounds based on experiments in 3, 6, 9 and $34 \mathrm{~m}$ long chutes. Tech. rep, Vedurstofa Islands, Reykjavik

Koch T, Greve R, Hutter K (1994) Unconfined flow of granular avalanches along a partly curved surface. II. Experiments and numerical computations. Proc R Soc A Math Phys Eng Sci 445(1924):415-435. https://doi.org/10.1098/rspa.1994.0069, rspa.1994.0069

http://rspa.royalsocietypublishing.org/cgi/doi/10.1098/

Kolb D (1984) Experiential learning: experience as the source of learning and development. Prentice Hall, Englewood Cliffs. https://doi.org/10.1016/B978-0-7506-7223-8.50017-4

Lee LM, Kassim A, Gofar N (2011) Performances of two instrumented laboratory models for the study of rainfall infiltration into unsaturated soils. Eng Geol 117(1-2):78-89. https://doi.org/10.1016/j. enggeo.2010.10.007, https://linkinghub.elsevier.com/retrieve/pii/S0013795210002115

Lewin K (1981) Games and simulations in science education. Int J Educ Dev 1(2):96-97. https://doi. org/10.1016/0738-0593(81)90018-3, https://linkinghub.elsevier.com/retrieve/pii/073805938190018 3

Lyons T (2006) Different countries, same science classes: students' experiences of school science in their own words. Int J Sci Educ 28(6):591-613. https://doi.org/10.1080/09500690500339621, http://www.tandfonline.com/doi/abs/10.1080/09500690500339621

Maltese AV, Tai RH (2010) Eyeballs in the fridge: sources of early interest in science. Int J Sci Educ 32(5):669-685. https://doi.org/10.1080/09500690902792385, https://www.tandfonline.com/doi/ full/10.1080/09500690902792385

Margreth S (2007) Defense structured in avalanche starting zones. Tech. rep, Swiss Federal Institute for Snow and Avalanche Research, Bern, Switzerland

Marín A, Vergara-Pinto F, Prado F, Farías C (2020) Living near volcanoes: scoping the gaps between the local community and volcanic experts in southern Chile. J Volcanol Geotherm Res 398:106903. https://doi.org/10.1016/j.jvolgeores.2020.106903, https://doi.org/10.1016/j.jvolgeores.2020.106903

McDougall S, Hungr O (2005) A model for the analysis of rapid landslide motion across three-dimensional terrain. Can Geotech J 41(6):1084-1097. https://doi.org/10.1139/t04-052

Mercer J, Gaillard JC, Crowley K, Shannon R, Alexander B, Day S, Becker J (2012) Culture and disaster risk reduction: lessons and opportunities. Environ Hazards 11(2):74-95. https://doi.org/10.1080/17477 891.2011.609876, http://www.tandfonline.com/doi/abs/10.1080/17477891.2011.609876

Ming Cheng Y, Hong Ivan Fung W, Li L, Li N (2019) Laboratory and field tests and distinct element analysis of dry granular flows and segregation processes. Nat Hazards Earth Syst Sci 19(1):181199. https://doi.org/10.5194/nhess-19-181-2019

Montessori M (1956) Montessori principles: the human tendencies and Montessori education. Montessori Association, Amsterdam

Mossoux S, Delcamp A, Poppe S, Michellier C, Canters F, Kervyn M (2016) Hazagora: Will you survive the next disaster?-A serious game to raise awareness about geohazards and disaster risk reduction. Nat Hazards Earth Syst Sci 16(1):135-147. https://doi.org/10.5194/nhess-16-135-2016

Muller CL, Roberts S, Wilson RC, Remedios JJ, Illingworth S, Graves R, Trent T, Henderson J, Wilkinson J, Wilkinson M, Desai A (2013) The Blue Marble: a model for primary school STEM outreach. Phys Educ 48(2):176-183. https://doi.org/10.1088/0031-9120/48/2/176, http://stacks.iop.org/00319120/48/i=2/a=176?key=crossref.9df5a2543a5708d615fe9b626c674067

Ng CWW, Choi CE, Goodwin GR, Cheung WW (2017) Interaction between dry granular flow and deflectors. Landslides 14(4):1375-1387. https://doi.org/10.1007/s10346-016-0794-3, http://link. springer.com/10.1007/s10346-016-0794-3

Ng CWW, Choi CE, Koo RCH, Goodwin GR, Song D, Kwan JSH (2018) Dry granular flow interaction with dual-barrier systems. Géotechnique 68(5):386-399. https://doi.org/10.1680/jgeot.16.P.273, https://www.icevirtuallibrary.com/doi/10.1680/jgeot.16.P.273

Paton D, Smith L, Daly M, Johnston D (2008) Risk perception and volcanic hazard mitigation: individual and social perspectives. J Volcanol Geotherm Res 172(3-4):179-188. https://doi.org/10.1016/j. jvolgeores.2007.12.026

Pereira G, Prada R, Paiva A (2014) disaster prevention social awareness: the stop disasters! case study. In: 2014 6th International conference on games and virtual worlds for serious applications (VSGAMES). IEEE, pp 1-8. https://doi.org/10.1109/VS-Games.2014.7012155, http://ieeexplore.iee. org/document/7012155/

Plattner T, Plapp T, Hebel B (2006) Integrating public risk perception into formal natural hazard risk assessment. Nat Hazards Earth Syst Sci 6(3):471-483. https://doi.org/10.5194/nhess-6-471-2006

Pouliquien O, Forterre Y (2002) Friction law for dense granular flows: application to the motion of a mass down a rough inclined plane. J Fluid Mech 453:133-151. https://doi.org/10.1017/S002211200 10067960108398 
Pudasaini SP, Hutter K (2007) Avalanche dynamics, vol 53. Springer Berlin Heidelberg, Berlin, Heidelberg. https://doi.org/10.1007/978-3-540-32687-8, http://link.springer.com/10.1007/978-3-54032687-8, arXiv: $1011.1669 \mathrm{v} 3$

Pudasaini SP, Wang Y, Sheng LT, Hsiau SS, Hutter K, Katzenbach R (2008) Avalanching granular flows down curved and twisted channels: theoretical and experimental results. Phys Fluids 20(7):073302. https://doi.org/10.1063/1.2945304

Savage SB, Hutter K (1991) The dynamics of avalanches of granular materials from initiation to runout. Part I. Analysis. Acta Mech 96:201-223. https://doi.org/10.1007/BF01176820

Smith K (2004) Environmental hazards, 4th edn. Routledge, London

Spence KJ, Guymer I (1997) Small-scale laboratory flowslides. Géotechnique 47(5):915-932. https://doi. org/10.1680/geot.1997.47.5.915, http://www.icevirtuallibrary.com/doi/10.1680/geot.1997.47.5.915

Spolverino G, Capparelli G, Versace P (2019) An instrumented flume for infiltration process modeling. Landslide triggering and propagation. Geosciences 9(3):108. https://doi.org/10.3390/geosciences 9030 108, https://www.mdpi.com/2076-3263/9/3/108

Terti G, Ruin I, Kalas M, Láng I, Cangròs I, Alonso A, Sabbatini T, Lorini V (2019) ANYCaRE: a roleplaying game to investigate crisis decision-making and communication challenges in weather-related hazards. Nat Hazards Earth Syst Sci 19(3):507-533. https://doi.org/10.5194/nhess-19-507-2019

Teufelsbauer H, Wang Y, Chiou MC, Wu W (2009) Flow-obstacle interaction in rapid granular avalanches: DEM simulation and comparison with experiment. Granul Matter 11(4):209-220. https://doi. org/10.1007/s10035-009-0142-6

Turkay S, Adinolf S (2012) What do players (think they) learn in games? Proc-Soc Behav Sci 46:33453349. https://doi.org/10.1016/j.sbspro.2012.06.064, https://linkinghub.elsevier.com/retrieve/pii/S1877 042812018009

United Nations (2015) Sendai framework for disaster risk reduction 2015-2030. United Nations, Sendai

Viroulet S, Baker JL, Edwards AN, Johnson CG, Gjaltema C, Clavel P, Gray JMNT (2017) Multiple solutions for granular flow over a smooth two-dimensional bump. J Fluid Mech 815:77-116. https://doi. org/10.1017/jfm.2017.41

Zhu TT, Zhang YJ (2017) An investigation of disaster education in elementary and secondary schools: evidence from China. Nat Hazards 89(3):1009-1029. https://doi.org/10.1007/s11069-017-3004-2, http:// link.springer.com/10.1007/s11069-017-3004-2

Publisher's Note Springer Nature remains neutral with regard to jurisdictional claims in published maps and institutional affiliations. 